\title{
Dumpster Optics: teaching and learning optics without a kit
}

Judy Donnelly, Nancy Magnani, Kathleen Robinson

Judy Donnelly, Nancy Magnani, Kathleen Robinson, "Dumpster Optics: teaching and learning optics without a kit," Proc. SPIE 9946, Optics Education and Outreach IV, 99460G (29 September 2016); doi: 10.1117/12.2238930

EviE Event: SPIE Optical Engineering + Applications, 2016, San Diego, California, United States 


\title{
Dumpster Optics - Teaching and learning optics without a kit Judy Donnelly ${ }^{* a}$, Nancy Magnani ${ }^{\mathrm{b}}$, Kathleen Robinson ${ }^{\mathrm{c}}$ \\ a36 Sycamore Terrace, Windham, CT 06280 \\ ${ }^{b}$ EASTCONN, 376 Hartford Turnpike, Hampton, CT 06247 \\ 'SPIE, 1000 20th Street, Bellingham, WA 98225
}

\begin{abstract}
The Next Generation Science Standards (NGSS) and renewed emphasis on STEM education in the U.S. have resulted in the development of many educational kits for teaching science in general and optics in particular. Many teachers do not have funding to purchase kits and practical experience has shown that even costly kits can have poorly written and misleading instructions and may include experiments that would not work in a classroom. Dumpster Optics lessons are designed to use inexpensive, commonly found materials. All lessons have been field-tested with students. We will describe the development of the lessons, provide examples of field testing experiences and outline possible future activities.
\end{abstract}

Keywords: Education, Low cost experiments, outreach, STEM, STEAM, web-based courses, professional development

\section{INTRODUCTION}

In the United States, the Next Generation Science Standards have put increased pressure on classroom teachers to teach subjects they are not familiar with or trained to teach, for example, by moving topics from one grade to another. In response, educational equipment suppliers have developed instructional kits, often expensive and not intuitive for teachers who often have scant science background. Companies may provide a few hours' training on kit use after which teachers return to the classroom to fend for themselves. We have seen that without clear instructions, including what should happen and what could go wrong in an experiment, teachers are less likely to successfully use the kits. In addition, some experiment designers have evidently never followed their own instructions with real students because the experiments could not possibly work as intended. In addition, once the initial supplies are depleted, teachers must purchase additional parts, which can be expensive.

\section{ORIGINS}

Between 2000 and 2006, the New England Board of Higher Education (NEBHE) in Boston, MA was funded by the Advanced Technological Education program of the National Science Foundation to develop curriculum and provide professional development for secondary and post-secondary educators in optics and photonics. The two three-year projects, along with a previous project in fiber optic technology (1995-1998), are collectively known as the PHOTON Projects. Each project gave participating teachers a $\$ 5000$ laboratory kit and provided professional development on using the kits in the classroom. A laboratory manual and set of videos for 26 different experiments was also developed and shared on the internet. ${ }^{1,2}$ During the PHOTON projects' workshops teachers would often bring their own favorite demonstration to share, usually performed with simple materials available in most school science laboratories or even at home. For example, one high school teacher demonstrated standing waves with a lightweight rope tied to a saber saw.

The PHOTON Projects PIs collected the teacher demonstrations and published them as the PHOTON Explorations ${ }^{3}$. By 2010 the collection included 16 inquiry-based experiments performed with the OSA Optics Discovery Kit (available for less than $\$ 20$ at Edmund Optics) plus commonly found materials such as an inexpensive laser pointer, flashlight and clothespins. In 2011, OSA funded the development and production of sixteen Explorations videos to be included in the Youth Education Media Library, http://www.osa.org/en-us/media library. Through a contract with NEBHE, student actors were hired from the Communication and Theater Departments of Eastern Connecticut State University in Willimantic, CT. Since they were not scientists, their reactions to the "magical" aspects of optics were genuine.

The PHOTON Explorations saw frequent use in the authors' outreach activities such as Laser Camp and Jr. Laser Camp for high school and fifth grade students respectively. While outreach introduces students to new ideas and perhaps piques their interest in further study, these were one-time events with little opportunity for personal interaction between facilitators and students. At SPIE's Optics and Photonics 2014, the authors met to discuss new ways to approach outreach with more

\footnotetext{
*jdonnelly@lasertechonline.org www.lasertechonline.org Phone: 860.786-8765
} 
in-depth lessons and at lower cost, and it was here that the name "Dumpster Optics" was coined. The concept was simple: Rather than relying on a purchased kit, Dumpster Optics activities would use commonly available materials, repurposed for use in optics. For example, a CD jewel case lined with black paper makes a serviceable vertically standing mirror for studying the law of reflection. With proper lighting, the same jewel case can be used to illustrate object and image distance in reflection. The $\mathrm{CD}$ itself can be stripped of metal coating and used as a diffraction grating. Any purchased materials (for example laser pointers or color LEDs) should cost no more than $\$ 2$.

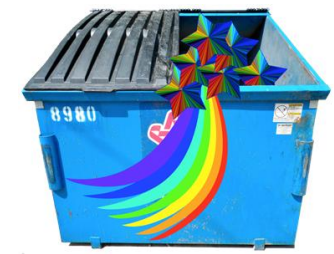

Figure 1. Dumpster Optics logo

Partly inspired by Don Herbert's 1952 book for children Mr. Wizard's Science Secrets ${ }^{4}$, Dumpster Optics groups several short inquiry-based activities into themed lessons of about 1-hour duration aimed at fifth grade students (10-12 years old). Many activities are from the PHOTON Explorations, others are adapted from books, the internet or workshops. Each lesson consists of PowerPoint slides with instructions for students, a separate pdf file of teacher notes, worksheets for recording student data and observations and links to the related Explorations videos. The teacher notes not only expand upon the slide instructions but also include suggestions on where to find materials. Because teachers who are not scientists may be hesitant to try unfamiliar activities, the notes explain what the outcome should be, what might go wrong and how to remedy the situation when things do go wrong. We have field-tested all activities with students from fifth grade to college freshmen and with SPIE support, presented workshops to teachers and graduate students at ETOP (Education and Training in Optics and Photonics) and at the Optics \& Photonics symposia.

\section{THE DUMPSTER OPTICS LESSONS}

\subsection{Current lessons}

As of this writing, eight lessons have been completed and at least two more are planned. They are available at no cost online at www.lasertechonline.org. Some popular outreach activities have not been included because they exceed the allowable cost. For example, we have yet to easily create an acceptable kaleidoscope without purchased mirrors. Although we have seen instructions on the web using various substitute reflectors they have been difficult to make, for example cutting hard plastic with a craft knife, or produce inferior results. The current list of Dumpster Optics lessons is in Table 1. The STEAM lessons include art, as well as science, technology, engineering and math (STEM). (Figure 2)

Table 1. Dumpster Optics Lessons

\begin{tabular}{|l|l|}
\hline \multicolumn{1}{|c|}{ Title } & \multicolumn{1}{|c|}{ Description } \\
\hline Light and Shadows & $\begin{array}{l}\text { Can you describe how light travels and use this model to show how a } \\
\text { pinhole camera works? }\end{array}$ \\
\hline Making Waves - The Colors of Light & $\begin{array}{l}\text { Are all red lights the same? Build a spectroscope from a cardboard tube and } \\
\text { an old CD and study the colors in the lights around you. }\end{array}$ \\
\hline Bending Light - Reflection & $\begin{array}{l}\text { What reflects light? Can you find a rule to predict the path of reflected } \\
\text { light? }\end{array}$ \\
\hline $\begin{array}{l}\text { Bending Light - Refraction (calculations } \\
\text { suitable for students who can handle powers of } \\
10)\end{array}$ & $\begin{array}{l}\text { How does light bend when it changes speed? Can you use the refraction of } \\
\text { light to do "magic" tricks? How can refraction be useful to people? }\end{array}$ \\
\hline Bending Light - Diffraction & $\begin{array}{l}\text { Does light always make a shadow when it's blocked by an object? What } \\
\text { happens when laser light passes around a hair? }\end{array}$ \\
\hline Seeing Color - Eyes and Art (STEAM lesson) & $\begin{array}{l}\text { An elementary introduction to vision and how your eyes can be fooled. Plus } \\
\text { one artist's experiments in color. }\end{array}$ \\
\hline Polarized Light Art (STEAM lesson) & $\begin{array}{l}\text { What is polarized light? How do polarized sunglasses work? And can you } \\
\text { use polarized light to make colorful art out of colorless transparent material }\end{array}$ \\
\hline What is a Laser? & $\begin{array}{l}\text { How do lasers work and what makes laser light different from light from a } \\
\text { flashlight? And why is laser not spelled with a "z"? }\end{array}$ \\
\hline
\end{tabular}


The Dumpster Optics lessons have been aligned to the NGSS standards (Grade 1: 1-PS4 Waves and their Applications in Technologies for Information Transfer and Grade 4: 4-PS4 Waves and their Applications in Technologies for Information Transfer). Details are on the web site.
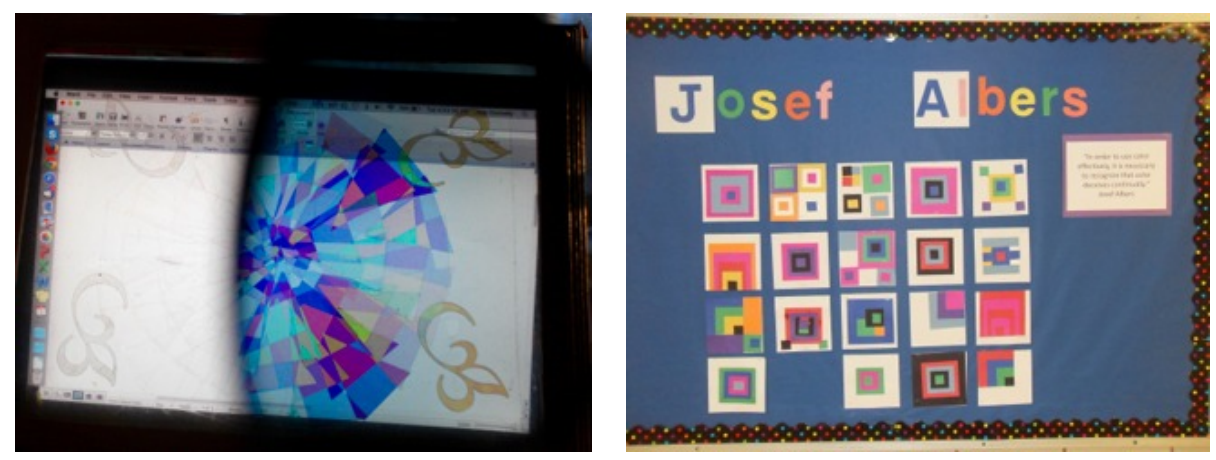

Figure 2. Dumpster Optics STEAM activities. (Left) Polarized light art using packing tape, laptop and polarized sunglasses. (Right) Student work from "Seeing Color - Eyes and Art" lesson, "Homage to the Square".

\subsection{A typical lesson: Reflection of Light}

The lesson was created to align with the science standards as well as in response to research showing that misunderstandings of the role of light in the visual system and can persist into adulthood. ${ }^{5,6,7}$ The materials list is provided in the teacher notes, along with suggestions for alternate materials (Table 2). We describe this lesson because it is the one for which we have the most complete field-testing reports. However, all of the lessons have the same format, with PowerPoint slides for students, detailed notes for teachers and links to video demonstrations.

Table 2. Materials needed for the Dumpster Optics reflection lesson

\section{MATERIALS:}

Activity 1 (Writing warm up activity- thinking about light):

- $\quad$ none required

Activity 2 and 3 (What color is a tennis ball? Does a tennis ball reflect light?):

Small rough textured white ball like a tennis ball or small styrofoam ball

- Flashlight

- Piece of thin red balloon (or other source of red light like a red LED)

Activity 4 (Categories - What reflects light?):

- Assortment of objects such as finished and unfinished wood samples, plastic or metal spoons, paper, cardboard, etc;

\section{Activity 5 (Law of Reflection):}

- Printed protractors (these are found on the Internet)

- Small mirrors that can be made to stand vertical. For this activity a CD jewel case lined with hlack naner will work- it can even stand verticallv on a table 
All activities include vocabulary necessary for understanding the lesson. In this case some of the terms should be familiar to fifth grade students, for example, "parallel" from fourth grade geometry. All words should be defined and discussed before the lesson (Figure 3). Vocabulary is reinforced as the lesson proceeds. Laser safety is introduced in any lesson using laser pointers.

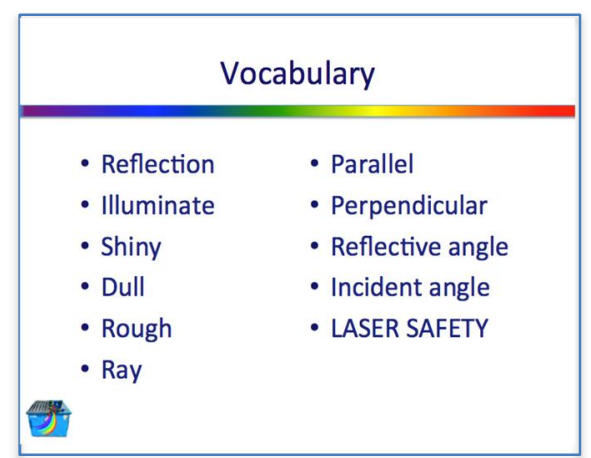

Figure 3. Vocabulary for the Dumpster Optics reflection lesson

This lesson begins with a "warm up" or reflection activity asking students to think about where light comes from and how they can see an object that is not itself emitting light. After students respond in writing to the prompt shown in Figure 4, the class discusses the sources of light striking the object and where the light goes after striking the object. Students are encouraged to think about how it is that they can see objects that do not emit light. We found that many students are very observant, noticing LED indicator lights and exit signs for example.

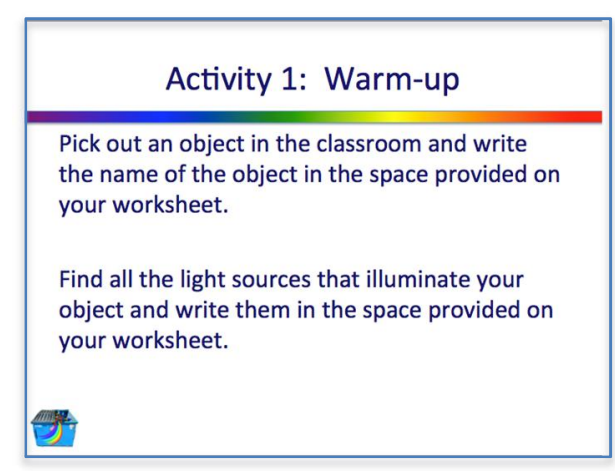

Figure 4. Prompt for warm up writing activity

On the pre-survey given to two groups of students in 2014 and 2015 more than $90 \%$ of fifth grade students (and many of their teachers) asked which common objects reflect light replied "a mirror". ${ }^{7}$ The qualitative part of the reflection lesson is an attempt to show that anything you can see reflects light from sources in the surroundings into your eyes. Students work with a partner and are first asked if a rough object like a tennis ball reflects light. (In practice, we were unable to find white tennis balls and so used white ping-pong or plastic foam balls.) As always, students first predict what they will see when the ball is illuminated with white and red light. After making and recording their observations, they engage in class discussion on the topic, "Do you think this rough object is reflecting light?" (Figure 5)

The next step is to devise a "reflection test", first by demonstrating with a mirror and flashlight that the light reflected from a mirror can be directed onto a table underneath where it illuminates the table with a bright spot of light. After observing that the rough ball does indeed reflect light onto the table students are given a bag of assorted household items-paper, cloth, plastic spoons, finished and unfinished wood, cardboard, etc. and asked to classify them as shiny, rough or dull. (Some items might go into more than one category.) Students then predict if each object will reflect light and then perform the "reflection test". (Figure 5) Results are discussed as a class. If a team of students finds that an object does not reflect light they are requested to try the test again to be sure. They are also invited to add their own items to test. By the end of the first set of activities, students should be convinced that everything they see reflects light. (Figure 6) 
Activity 2: What color is a tennis ball?

- Turn off the lights. Shine a flashlight on the tennis ball. What color is the ball? Why?

- Put a red filter over the flashlight. What color is the tennis ball now? Why?

Do you think this rough object is reflecting light?

\section{Activity 3: Does a tennis ball reflect light?}

- Shine the flashlight upward at the ball so the light doesn't directly hit the table.

- Put the ball a few inches from the flashlight. Look at the table under the ball. What do you see? Where did the light come from?

- If there is time, repeat with the red balloon over the flashlight.

- Does a rough ball reflect light?

尚羿

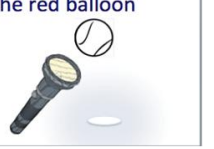

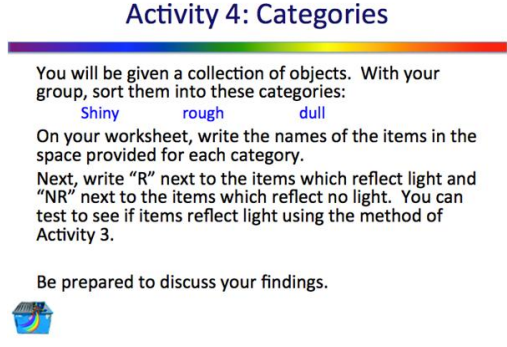

Figure 5. Do rough objects reflect light?
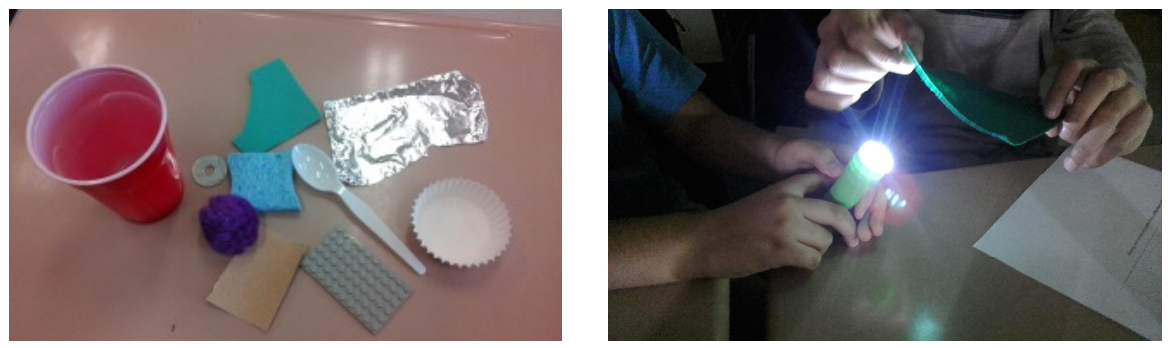

Figure 6. Students test a variety of materials to see if they reflect light onto the table.

The quantitative part of the lesson uses a laser pointer and begins with a discussion of laser safety. From the teacher notes, Review laser safety before handing out any materials. Either provide the students with rules or have them come up with rules such as keep lasers flat on the table, only turn laser on for the duration of the measurement, be aware of other students, make sure your beam doesn't go beyond the edge of your work space (block with a book or other object) and no high sticking with the laser beam. Make sure they understand the consequences of breaking these rules, for example, they will lose the privilege of using a laser pointer.

To avoid having to locate small rectangular mirrors and then attach them to blocks to make them stand upright, the instructions specify CD jewel cases with the front side lined with black paper. The "mirror" will stand vertically when it is partially opened. Printable protractors can be found easily with an internet search. Students may need a refresher on how to measure angles. Students are asked to make a prediction before measuring the reflected angle and for each incident angle students record and then discuss their results and to determine if they agree. If there is disagreement, students can offer some reasons for the discrepancy. One common error is to be careless with the placement of the reflecting surface on the zero line of the protractor. After several angles have been measured, students are asked to make up a rule for reflection. The PowerPoint slide show includes animations illustrating the law of reflection and the difference between reflection from a mirror and from a rough surface. (Figure 7)
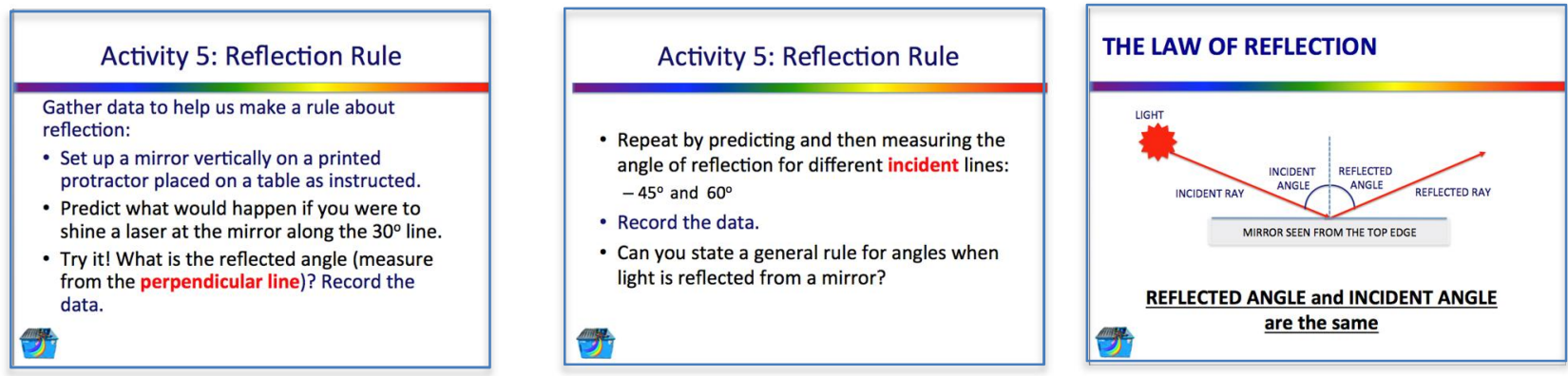

Figure 7. Instructions for determining law of reflection. The graphic (and the two slides following, not shown) are animated. 
The lesson also includes optional applications of the law of reflection that require more expensive materials or include the concept of imaging. For example, "Who can see the teddy?" uses a long mirror (the type sold for walls or doors) and asks which of several students placed in front or to the side of the mirror can see the reflection of an object held by the teacher. The optional application activities can be used to test student knowledge of reflection.

\section{USING THE LESSONS}

\subsection{Classroom field-testing}

All of the individual activities have been used either in classrooms (including high school and college where deeper learning is expected) or outreach, and most of the lessons have also been classroom tested. During the 2014-2015 academic year, six Connecticut fifth grade classrooms (123 students) participated in field-testing of the reflection lesson. A 3question pre-test was administered two weeks before the lessons and post-testing took place 2 weeks and again 6 weeks afterward. As reported in Magnani and Donnelly ${ }^{8}$ students showed moderate improvement in understanding reflection after completing the Dumpster Optics lesson. We were surprised, however, that on the first post-test only $28 \%$ of students answered that light is reflected by all objects in a list (compared to $8 \%$ on the pre-test). In their written comments, many students remarked that they were surprised to learn this fact about light so it was odd that so few answered the question correctly. We repeated the question on pre- and post-tests in the 2015-2016 school year and found similar results. After discussion with elementary education experts we conclude that the question is not worded correctly for students who are novices at multiple-choice questions and that their written comments are a more reliable indicator of understanding. In addition, some students may have a lower reading comprehension level which may impact their understanding of the question.

\subsection{Workshops}

Although SPIE has sponsored hands-on PHOTON Explorations workshops for many years (often with the title "Optics Outreach Magic"), the first official Dumpster Optics workshop was held with SPIE support in July 2015 at ETOP (Education and Training in Optics and Photonics) in Bordeaux, France. The ETOP workshop was the first to encourage attendees to bring their school-aged children. We noted that adult participants seemed to be more willing to try the simple activities with their children than working alone in previous all-adult workshops. In August 2015 a second Dumpster Optics workshop was held at SPIE's Optics and Photonics conference in San Diego, CA. O\&P participants gave helpful suggestions for organizing the materials to allow more time for experimentation with less time spent passing out supplies. Future workshops will feature materials packed in individual bags for easy distribution. (Figure 8)

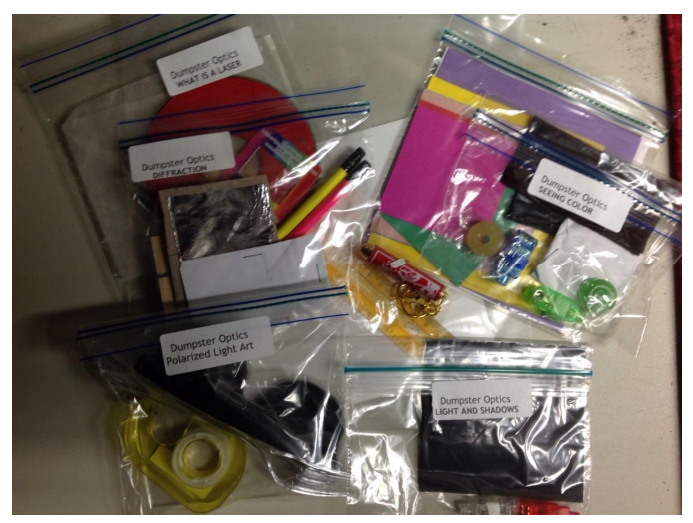

Figure 8. Materials for five Dumpster Optics activities packaged in individual labeled lunch bags.

\section{FUTURE PLANS}

The original Dumpster Optics lessons included the teacher notes on the PowerPoint slides. At its winter meeting in 2016, the SPIE Education and Outreach Committee endorsed the separation of slides and notes with notes being available as a separate pdf document. Five of the eight lessons have been separated as of July 2016, with expanded teacher notes edited by members of the Outreach and Standards Subcommittee. Subcommittee members have suggested that once final editing 
is complete the lessons could be converted to other languages beginning with Spanish. SPIE has purchased the website DumpsterOptics.org and it is the society's intent to make all of the Dumpster Optics resources (lessons, teacher notes, power point slides, materials lists and videos) available to the community on that website.

In the NGSS, light and color has been moved from upper elementary classrooms to $1^{\text {st }}$ grade (generally students are 6-7 years old). Future plans for Dumpster Optics include adaptation of these lessons to the $1^{\text {st }}$ grade classroom. This is very important since this group of teachers rarely teaches science and will need lessons that incorporate teacher notes and demonstrations. Previously, the PHOTON Explorations were used to provide hands-on "home labs" in web-based courses for both teachers and photonics industry technicians. Professional development could be offered to teachers online or at national or regional conferences, using the Dumpster Optics lessons to teach optics content to this new population of teachers. Ongoing support and mentorship via email or threaded discussions will be vital to supporting teacher adaptation of the materials.

\section{CONCLUSION}

Eight Dumpster Optics lessons have been developed, aligned to NGSS and successfully used in classrooms. The lessons do not require specialized or expensive materials and include detailed information for teachers. New lessons will be added to the collection as time permits. The lessons can serve as the basis of web-based professional development for teachers.

\section{ACKNOWLEDGEMENTS}

Project PHOTON: A Curriculum Development, Teacher Enhancement and Laboratory Development Project Funded in part by the Advanced Technology Education program of the National Science Foundation. (NSF/DUE \#0053284)

Project PHOTON2: Web-based Collaborative Learning for Teachers

Funded in part by the Advanced Technology Education program of the National Science Foundation. (NSF/DUE 0302528)

\section{REFERENCES}

[1] J. Donnelly and N. Massa, " Labs for the PHOTON/PHOTON2 Experiment Kit", www.nebhe.org/wp-content/uploads/PHOTON2_Lab_Kit_Manual.pdf

[2] J. Donnelly and N. Massa, PHOTON/PHOTON2 Lab Videos www.youtube.com/playlist?list=PL31J9U7X1_N2eFG9NIN-gsTPE4tYnUHCM

[3] J. Donnelly, K. Amatrudo, K. Robinson, and F. Hanes, "The PHOTON Explorations: Sixteen Activities, Many Uses," in ETOP 2013 Proceedings, M. Costa and M. Zghal, eds., (Optical Society of America, 2013), paper EWC5.

[4] D. Herbert, Mr. Wizard's Science Secrets, Popular Mechanics Press (1952).

[5] Krall, Rebecca McNall; Christopher, John E.; Atwood, Ronald K., "Comparison of Central Appalachian In-Service Elementary and Middle School Teachers' Understanding of Selected Light and Force and Motion Concepts", Science Educator, v18 n1 p1-16 Spr 2009

[6] Winer GA1, Cottrell JE, Gregg V, Fournier JS, Bica LA., "Fundamentally misunderstanding visual perception. Adults' belief in visual emissions", Am Psychol. 2002 Jun-Jul;57(6-7): 417-24.

[7] Gregg, V.R., Winer, G. A., Cottrell, J. E., Hedman, K. E.,Fournier, J. S., " The persistence of a misconception about vision after educational interventions ", Psychonomic Bulletin \& Review 2001, 8 (3), 622-626.

[8] N. Magnani and J. Donnelly, "Teaching reflection to teachers and students", in Proceedings Volume 9793: Education and Training in Optics and Photonics: ETOP 2015, October 2015. 